\title{
Regulation of p53: a collaboration between Mdm2 and MdmX
}

\author{
Dongsheng Pei ${ }^{1,2}$, Yanping Zhang ${ }^{1,2}$ and Junnian Zheng ${ }^{1}$ \\ ${ }^{1}$ Laboratory of Biological Cancer Therapy, Xuzhou Medical College, Xuzhou, China \\ 2 Department of Radiation Oncology and Lineberger Comprehensive Cancer Center, School of Medicine, the University of \\ North Carolina at Chapel Hill, Chapel Hill, NC, USA \\ Correspondence to: Yanping Zhang, email: ypzhang@med.unc.edu \\ Junnian Zheng, email: jnzheng@xzmc.edu.cn \\ Keywords: Mdm2, MdmX, p53, cancer
}

Received: February 17, 2012, Accepted: March 2, 2012,

Published: March 10, 2012

Copyright: @ Pei et al. This is an open-access article distributed under the terms of the Creative Commons Attribution License, which permits unrestricted use, distribution, and reproduction in any medium, provided the original author and source are credited.

\section{ABSTRACT:}

\begin{abstract}
p53 plays an important role in the regulation of the cell cycle, DNA repair, and apoptosis and is an attractive cancer therapeutic target. Mdm2 and MdmX are recognized as the main p53 negative regulators. Although it is still unknown why Mdm2 and MdmX both are required for $\mathrm{p} 53$ degradation, a model has been proposed whereby these two proteins function independent of one another; Mdm2 acts as an E3 ubiquitin ligase that catalyzes the ubiquitination of p53 for degradation, whereas MdmX inhibits p53 by binding to and masking the transcriptional activation domain of p53, without causing its degradation. However, Mdm2 and MdmX have been shown to function collaboratively. In fact, recent studies have pointed to a more important role for an $\mathrm{Mdm2} / \mathrm{MdmX}$ coregulatory mechanism for p53 regulation than previously thought. In this review, we summarize current progress in the field about the functional and physical interactions between Mdm2 and MdmX, their individual and collaborative roles in controlling p53, and inhibitors that target $\mathrm{Mdm} 2$ and $\mathrm{MdmX}$ as a novel class of anticancer therapeutics.
\end{abstract}

\section{INTRODUCTION}

The p53 tumor suppressor plays a pivotal role in regulating cellular processes including cell cycle arrest, apoptosis, cell metabolism and senescence. Mutation of the TP53 gene or inactivation of the p53 signaling pathway occurs at a high frequency in many human tumors, suggesting that p53 plays a critical role in preventing normal cells from becoming cancerous. p53 is a stressinducible protein; it is inactive under normal physiological conditions and activated in response to various types of stresses such as DNA damage and ribosomal stress [1]. Activated p53 can either induce cell cycle arrest and inhibit cell growth or promotes cell apoptosis depending on different type of stress and the cellular context. Multiple mechanisms have been revealed to collectively accomplish the regulation of p53 activity [2,3], which ultimately determines the selectivity of p53 for specific transcriptional targets, resulting in precise control of the p53 activity.

p53 is the most frequently inactivated tumor suppressor gene in human cancer. Clinical studies have shown that p53 is mutated in approximately $50 \%$ of human cancers. Mdm2 and MdmX (also known as MDM4) are two structurally related proteins that play a critical role in downregulating p53 activity in embryonic cells and stem cells under normal conditions [4]. Therefore, the amplification and/or aberrant expression of Mdm2 and MdmX occur in a number of tumors of diverse origin, especially in tumors that retain wild-type p53.

Mdm2 (murine double minute 2) was discovered on double minute chromosomes in a derivative cell line of NIH-3T3 cells $[5,6]$. Mdm2 belongs to the family of E3 ubiquitin ligases that contain a RING [really interesting new gene] domain [7] and serves as the major E3 ubiquitin ligase for $\mathrm{p} 53$ degradation. Several studies have illustrated the importance of $\mathrm{Mdm} 2$ in the control of $\mathrm{p} 53$ activity. The mechanism by which Mdm2 suppresses $\mathrm{p} 53$ has classically been thought to occur by two distinct ways: by binding to the N-terminal domain of p53 and masking p53's access to transcriptional machinery, and by ubiquitinating p53 and targeting it for proteasomal degradation [8-11]. However, recent research has shown that Mdm2-p53 binding alone in the absence of Mdm2 E3 ubiquitin ligase activity is insufficient to suppress p53 activity [12].

MdmX has been identified as a highly homologous 
gene that is closely related to Mdm2 [13,14]. Similarly to $\mathrm{Mdm} 2$, MdmX possesses a p53 binding domain at its $\mathrm{N}$-terminus and a RING finger domain at its $\mathrm{C}$-terminus through which it heterodimerizes with Mdm2. However, unlike Mdm2, MdmX does not have appreciable ubiquitin ligase activity. Because of its sequence similarity with $\mathrm{Mdm} 2$ and its ability to inhibit p53-induced transcription when overexpressed, $\mathrm{MdmX}$ has been hypothesized to act as a negative regulator of $\mathrm{p} 53$ through physical binding [15].

\section{MODELS FOR THE REGULATION OF P53 BY MDM2 AND MDMX}

Genetic evidences have shown that $\mathrm{Mdm} 2$ and $\mathrm{MdmX}$ are the two essential negative regulators of $\mathrm{p} 53$, since the concomitant deletion of $\mathrm{p} 53$ can rescue the embryonic lethality caused by the deletion of either Mdm2 or MdmX. The fact, neither Mdm2 nor MdmX can compensate for one another in vivo to inhibit $\mathrm{p} 53$ suggests that Mdm2 and MdmX perform critical, non-overlapping functions in p53 suppression. The requirement of both $\mathrm{Mdm} 2$ and $\mathrm{MdmX}$ raises the question as to why p53 needs two highly similar regulators. A proposal has been put forward whereby these two homologous proteins can function independently: Mdm2 functions as an E3 ubiquitin ligase that catalyzes the ubiquitination of $\mathrm{p} 53$, $\mathrm{MdmX}$, and itself for proteosomal degradation [16-18], whereas MdmX functions mainly by binding to and masking the transcriptional activation domain of p53.

Mdm2 and MdmX physically interact with and functionally affect each other. $\mathrm{Mdm} 2$ can form a homodimer in vitro, but it is also capable of forming a more stable heterodimer with MdmX through their RING domains $[19,20]$. In vitro transfection studies have indicated that $\mathrm{MdmX}$ stabilizes Mdm2 by interfering with Mdm2 autoubiquitination. However, MdmX has also been reported to be ubiquitinated and degraded by Mdm2 [18]. Other studies have shown that MdmX is able to inhibit Mdm2-mediated p53 degradation by competing with $\mathrm{Mdm} 2$ for $\mathrm{p} 53$ binding resulting in the accumulation of p53 [20-22].

Many lines of evidence point to an intricate interaction that exists between $\mathrm{Mdm} 2$ and $\mathrm{MdmX}$ in p53 regulation [23-27]. $\mathrm{Mdm} 2$ and $\mathrm{MdmX}$ proteins are found to exist in cells predominantly in the form of a heteroduplex [25], and structural studies have predicted that the formation of an Mdm2-MdmX heteroduplex is structurally favored over the formation of homoduplexes of either protein [28]. It has been shown that Mdm2 alone is a relatively inefficient E3 ubiquitin ligase [25], but becomes more efficient at ubiquitinating p53 after heterodimerization with MdmX [26]. A previous genetic study in the development of the mouse central nervous system (CNS) has revealed a synergistic role between $\mathrm{Mdm} 2$ and MdmX, as well as independent functions of
Mdm2 and MdmX for $\mathrm{p} 53$ inhibition. In this study, mice lacking Mdm2 in the CNS developed hydranencephaly at embryonic day 12, whereas mice in which $\mathrm{MdmX}$ was deleted in the CNS showed a proencephaly phenotype at embryonic day 17.5. Interestingly, the simultaneous deletion of both genes resulted in an even earlier and more severe CNS phenotype. All of these phenotypes were rescued by the concomitant deletion of p53. These observations strongly support a synergistic relationship between Mdm2 and MdmX in the inhibition of p53 activity during the development of the CNS [29]. Based on both in vitro and in vivo studies, another, perhaps more convincing model was proposed in which Mdm2 and MdmX work together to control p53 activity [30,31].

In order to determine whether Mdm2-p53 binding alone is sufficient to suppress p53 activity, or whether Mdm2-mediated ubiquitination is also required in that regard, Itahana et al. [12] generated knock-in mice harboring a single point mutation $(\mathrm{C} 462 \mathrm{~A})$ in one of the zinc-coordinating residues in the $\mathrm{C}$-terminal RING domain of Mdm2 that is critical for the E3 ubiquitin ligase activity of Mdm2. The homozygous C462A mutation was embryonic lethal and the lethality was rescued by the concomitant deletion of $\mathrm{p} 53$, providing evidence that the Mdm2 RING domain is required for the regulation of p53 activity in vivo. This study used an inducible $\mathrm{p} 53^{\mathrm{ER}}$ system that allowed the investigators to induce the expression of p53 ex vivo in mouse embryonic fibroblast (MEF) cells to study the interactions of p53 in the Mdm2 mutant background. Upon induction of p53 in MEF cells, Itahana et al. demonstrated that the Mdm2 RING mutant protein, although deficient in the ability to ubiquitinate p53, is fully capable of binding to $\mathrm{p} 53$ proving that $\mathrm{Mdm} 2$ cannot suppress p53 transcriptional activity through binding alone. However, the authors also showed that the C462A mutation alters the structure of the Mdm2 RING domain to the extent that the Mdm2 C462A mutant is unable to heterodimerize with MdmX. Therefore, the study cannot explain whether $\mathrm{Mdm} 2$ and $\mathrm{MdmX}$ interaction is required for $\mathrm{p} 53$ suppression.

Recently, two studies using MdmX RING domain mutant knock-in alleles demonstrated that the RING domain of $\mathrm{MdmX}$, like that of Mdm2, is also critical for regulating p53 activity during early embryogenesis $[32,33]$. In the Huang et al. study, mice harboring an MdmX C462A mutation in one of the critical zinccoordinating residues of the RING domain died at approximately day 9.5 of embryonic development as the result of an increase in apoptosis and a decrease in cell proliferation. The concomitant deletion of $\mathrm{p} 53$ completely rescued the embryonic lethality of the MdmX C462A mutation [32]. Importantly, the authors showed that the MdmX C462A mutant protein does not bind to Mdm2, yet it retains the ability to bind to p53 to the same degree as wild-type MdmX. These results indicate that even though both Mdm2 and MdmX are fully capable of 
binding to $\mathrm{p} 53$ individually, the disruption of the Mdm2MdmX heterocomplex causes p53 activation in vivo. In a similar study performed by Pant et al., the authors used a tamoxifen-based Cre-inducible MdmX $\triangle \mathrm{RING}$ allele to investigate the role of $\mathrm{Mdm} 2-\mathrm{MdmX}$ heterodimerization in Mdm2 and p53 regulation. They found that although the heteroduplex is essential during embryonic development, heterodimerization is dispensable during the adult life of the mouse. Together, these studies provide compelling evidence that the action of the heterodimer of Mdm2 and $\mathrm{MdmX}$, and not necessarily the independent action of either protein is crucial to the appropriate control of p53. However, these studies cannot answer a remaining question as whether the Mdm2 E3 ubiquitin ligase function is still required for $\mathrm{p} 53$ suppression, because the Mdm2 RING mutation simultaneously disrupts its E3 ligase function and its binding to $\mathrm{MdmX}$, and because in vitro studies have shown that $\mathrm{Mdm} 2$ by itself is a relatively weak E3 for p53 degradation and its heterodimerization with MdmX enhances its E3 activity $[25,26]$. Thus, the generation and analysis of mutations that block the ubiquitin ligase activity but do not affect the heterodimerization between $\mathrm{Mdm} 2$ and $\mathrm{MdmX}$ in vivo, if technically possible, would be essential for understanding the importance of the in vivo cooperation between Mdm2 and MdmX.

\section{THE MDM2/MDMX RATIO DETERMINES P53 STABILITY AND ACTIVITY}

Although Mdm2 and MdmX have a synergistic relationship that effectively inhibits p53, as discussed above, Mdm2 and $\mathrm{MdmX}$ also have independent roles in the regulation of $\mathrm{p} 53 . \mathrm{MdmX}$ can inhibit p53 transcriptional activity by interfering with the ability of p53 to interact with the basal transcription machinery, while Mdm2 can target p53 for degradation. Several studies have reported that elevated MdmX levels stabilize p53 by inhibiting Mdm2-mediated p53 degradation without interfering significantly with Mdm2-dependent p53 ubiquitination [21,22,34,35]. Transfection studies have also provided evidence that MdmX can stabilize $\mathrm{Mdm} 2$ by interfering with auto-ubiquitination and degradation of Mdm2 [34]. Conversely, results from Linares et al. have shown that MdmX stimulates Mdm2mediated ubiquitination of $\mathrm{p} 53$, as well as Mdm2 selfubiquitination in vitro [26]. These inconsistent data reflect the complex relationship between Mdm2 and MdmX and are often difficult to reconcile because of the nature of in vitro overexpression studies. Quantitative analysis has demonstrated that the level of endogenous MdmX is present at different proportion to that of $\mathrm{Mdm} 2$ in several types of human cell lines [36]. This observation might well account for the discrepancies when trying to examine the effect by altering the $\mathrm{MdmX}$ abundance in various in vitro studies and also indicates the relative level of Mdm2 and $\mathrm{MdmX}$ is crucial for controlling p53 stability and activity, which was further demonstrated by the recent crystal structures studies. Linker et al. revealed that the primary and secondary interfaces in Mdm2 homodimers or Mdm2/MdmX heterodimers are crucial for the binding of ubiquitin E2 enzyme and ubiquitylation of the subunit. Because Mdm2 homodimers have two primary and secondary interfaces for ubiquitin E2 enzyme binding and the E2 enzyme can be recruited by either monomer, which will lead to the ubiquitylation of the other subunit. However, in the Mdm2/MdmX heterodimer, only Mdm2 can provide the primary E2 interaction site while the secondary interface will be provided by $\mathrm{MdmX}$, which will not cause the ubiquitylation and degradation of Mdm2. Therefore, the ratio of $\mathrm{Mdm} 2 / \mathrm{MdmX}$ can be used to explain Mdm2 status in different situations: Mdm2 will form homodimer and degrade by itself through ubiquitination if the ratio is high, on the contrary, Mdm2 will be stabilized if the ratio is low [37].

Both in vivo and in vitro experiments have demonstrated that p53 can bind to p53-responsive elements located within the $\mathrm{Mdm} 2$ gene and promote its transcription thereby set up a negative feedback regulatory loop $[38,39]$, while in contrast p53 cannot transactivate MdmX. Because of this, the protein level of Mdm2 fluctuates widely upon p53 activation, whereas since $\mathrm{MdmX}$ is not a p53 transcriptional target, the level of MdmX remains relatively constant. Thus, the stressinduced up-regulation of p53 increases the levels of $\mathrm{Mdm} 2$ thereby modulating the ratio of $\mathrm{Mdm} 2$ to $\mathrm{MdmX}$ and serving as a negative feedback loop by which p53 can regulate itself. When the level of MdmX is higher than the level of Mdm2, MdmX will inhibit Mdm2-mediated p53 degradation resulting in the stabilization of the level of Mdm2 through the stabilization of $\mathrm{p} 53$. In this proposed feedback loop, MdmX acts as a sensor of the concentration of $\mathrm{Mdm} 2$ and controls the balance between $\mathrm{Mdm} 2$ and $\mathrm{p} 53$.

\section{MDM2AND MDMXINP53UBIQUITINATION}

It has been widely accepted that $\mathrm{Mdm} 2$ antagonizes p53 by promoting its ubiquitination and proteasomedependent degradation $[8,10]$. In addition to the polyubiquitin-dependent degradation of $\mathrm{p} 53, \mathrm{Mdm} 2$ can also promote monoubiquitination of $\mathrm{p} 53$; this does not directly cause $\mathrm{p} 53$ degradation, but can promote the export of p53 from the nucleus to the cytoplasm especially to the mitochondria and further promote other kinds of modification of p53 [40,41]. In vitro studies have shown 
that DNA damage can destabilize Mdm2 by means of autoubiquitination [39,42] and Mdm2 ubiquitinates MdmX to mark it for proteasomal degradation $[43,44]$. As discussed above, MdmX does not have appreciable ubiquitin ligase activity, but $\mathrm{MdmX}$ has been proposed to inhibit $\mathrm{p} 53$ by binding to the $\mathrm{N}$-terminal transcription activation domain of p53 [13]. This binding inhibits p53 activation by hampering the interaction p53 with p300, as acetylation of p53 by p300 can lead to p53 activation and increased transcriptional activity [45]. Consistently, increased endogenous p53 acetylation level is observed in MdmX-null cells. Furthermore, it has been reported that several lysine residues at the $\mathrm{C}$-terminal region of p53 involved in the acetylation are also the same sites of Mdm2-mediated ubiquitination [46]. Thus, it is conceivable that MdmX might indirectly stimulate the Mdm2-mediated ubiquitination of p53 through decreasing the acetylation. Together with the observation that the Mdm2-MdmX heterodimer is a more effective E3 ligase for p53 ubiquitination than Mdm2 alone [26], these data support a model in which the Mdm2-MdmX complex is more efficient in targeting p53 for ubiquitination and degradation.

Ubiquitin-conjugating enzymes (E2s) have a dominant role in determining which of the lysine residues are used for polyubiquitination. Like many other RING domain proteins, the Mdm2 RING domain can promote the transfer of ubiquitin molecules from an E2 conjugating enzyme directly to the lysine residues of the target substrates [47]. Because the E2 enzyme decides the type and length of ubiquitin linkage [48], it is important to identify which E2s are recruited to the Mdm2-MdmX complexes. In vitro studies have shown that UbcH5 functions as an E2 enzyme for Mdm2-induced p53 ubiquitination and degradation [49]. Whether UbcH5 functions in vivo as the main E2 for Mdm2, or whether there are other E2 enzymes that interact with Mdm2 remains to be determined. A recent study [50] has shown that E2 enzyme in the absence of the appropriate E3 ubiquitin ligase is sufficient to promote the ubiquitination of the substrate. Based on the results of this study, the authors conclude that the main function of E3 ligases include: to specify the lysines to be ubiquitinated, to specify the conformation of ubiquitination, to specify mono versus polyubiquitination, and to define the target region on the substrate to be ubiquitinated.

\section{PHOSPHORYLATION OF MDM2 AND MDMX}

In addition to ubiquitination as a mechanism of controlling $\mathrm{Mdm} 2$ and $\mathrm{MdmX}$, the activity of these proteins depends on their phosphorylation status. A number of kinases have been reported to phosphorylate $\mathrm{Mdm} 2$ and $\mathrm{MdmX}$ at different residues. DNA damage stimulates activation of multiple kinases including ataxia telangiectasia mutated (ATM) [51], checkpoint kinases 1 and 2 (Chk1 and Chk2) [52], DNA-dependent protein kinase (DNA-PK), and c-Abl kinase, which leads to the phosphorylation of both Mdm2 and $\mathrm{MdmX}[53,54]$. Evidence supports the idea that the phosphorylation of Mdm2 by ATM inhibits Mdm2 RING domain homodimerization, which prevents the polyubiquitination of p53 [55]. In addition, ATM and Chk2 have been shown to phosphorylate and destabilize MdmX [56-59]. Another protein that has been shown to regulate Mdm2 and MdmX phosphorylation status is Wip1, which is a phosphatase that can specifically dephosphorylate Mdm2 at Ser395 and MdmX at Ser403 increasing their stability and inhibiting p53 activity [60,61].

The dimerization of $\mathrm{Mdm} 2$ and $\mathrm{MdmX}$ and Mdm2's E3 ligase function also appear to be regulated by phosphorylation. In an MdmX3SA (Ser-341, -367 and -402 to alanine) knock-in mouse model, Mdm2 retains the ability to bind to MdmX, but is significantly reduced in its capacity to degrade MdmX, resulting in an increase in the concentration of Mdm2-MdmX heterodimers [62]. Thus, the observed defect in p53 stabilization in MdmX3SA mice could be due to the presence of high levels of Mdm2-MdmX complexes. This study also found an approximately $50 \%$ reduction in the basal p53 activity in MdmX3SA mice indicating that the stoichiometric balance between $\mathrm{Mdm} 2$ and $\mathrm{MdmX}$ is crucial for $\mathrm{p} 53$ activation and its response to DNA damage stress in vivo.

\section{INHIBITORS TARGETING MDM2 AND MDMX}

Although approximately $50 \%$ of cancers harbor p53 mutations, the other $50 \%$ of cancers retain WT p53, yet they remain uninhibited by the tumor suppression activity of $\mathrm{p} 53$. This is generally accomplished through the overexpression of $\mathrm{Mdm} 2$ or MdmX by gene amplification or mutation. It has been accepted, at least theoretically, that reactivation or restoration of the p53 function in tumors is a promising cancer therapeutic strategy. Some proposed strategies include repressing the expression of $\mathrm{Mdm} 2$, blocking the p53-Mdm2 interaction, and inhibiting the ubiquitin ligase activity of Mdm2 [63,64]. For example, Nutlin, a small molecule that inhibits Mdm2, can trigger cell-cycle arrest and apoptosis and exhibits antitumor efficacy in a murine xenograft model [65]. Several studies also revealed that rational combination of Nutlin-3a and other drugs could potentiate chemotherapy with mitotic inhibitors against cancer and protect normal cells from cytostatic agent $[66,67]$. However, still several issues have been raised from studies of Nutlin. One of them is the high toxicity of inhibiting Mdm2 by Nutlin. Studies in mice indicate that Mdm2 loss leads to induction of p53 activation and p53-dependent pathologies in both proliferating and quiescent cells, such as erythroid progenitor cells, neurons and smooth muscle cells [68]. 
Another limitation with Nutlin is that although Nutlin kills cancer cells that express elevated Mdm2, tumor cells overexpressing MdmX have poor response to Nutlin due to its low binding affinity for MdmX compared to Mdm2. As an alternative route for $\mathrm{p} 53$ inhibition, overexpression of MdmX in tumor cells has been observed. This will decrease the efficacy for anti-Mdm2-based cancer therapy. Therefore, the development of compounds targeting both Mdm2 and MdmX in tumors retaining WT p53 has become a promising therapeutic goal.

Recently, Bernal et al. [69] showed in both in vitro and in vivo experiments that a "stabilized alpha-helix" of p53 peptide, SAH-p53-8, preferentially inhibits the binding of p53 with $\mathrm{MdmX}$ and reduces cancer cell viability, thereby overcomes MdmX-mediated cancer resistance. SAH-p53-8 is derived from the so-called "stapled" peptides SAH-p53 that was designed based on the peptide sequence of the p53 transactivation domain. This peptide show protease resistant combined with increased cellular uptake properties due to a chemical designed strategy termed "hydrocarbon stapling", which can mimic the biological function of the nature $\alpha$-helical structure. Co-immunoprecipitation experiments indicate that this peptide can bind to both Mdm2 and MdmX within the cells. Although SAH-p53-8 exhibits a 25-fold greater binding preference for $\mathrm{MdmX}$ over Mdm2, it has been shown to have the ability to kill cancer cells that overexpress Mdm2, MdmX, or both of the proteins. More importantly, SAH-p53-8 has been shown to efficiently induce a tumor-suppressive response in vivo. The study provides a clue to reactivate p53 tumor suppressor function by synergistically applying $\mathrm{Mdm} 2$ and $\mathrm{MdmX}$ inhibitors in cancer cells, and affords new therapeutic opportunities for simultaneously inhibiting both Mdm2 and $\mathrm{MdmX}$ to restore p53 using drug combinations or dual-inhibitory drugs [70-72]. Thus, efficient rescue of p53 by pharmacological drugs targets Mdm2-MdmX hetero-oligomers is conceptually viable.

\section{CONCLUDING REMARKS}

Over the past decade, considerable progress has been made towards understanding the regulation of p53 by $\mathrm{Mdm} 2$ and $\mathrm{MdmX}$, and much of which has come from data obtained from various mouse models. It is generally accepted that the ubiquitination of p53 is a fundamental mechanism of p53 control and that Mdm2 is the principal p53 ubiquitin ligase [36,73]. A study of an Mdm2 RING finger mutant knockin mouse model [12] has shown that Mdm2 is in fact not regulated by autoubiquitination in vivo, nor is it capable of blocking p53 activity by binding alone. This is consistent with an earlier report that small molecules that inhibit the E3 ubiquitin ligase activity of Mdm2 can activate p53 $[10,74]$. However, the exact mechanism underlying the degradation of $\mathrm{p} 53$, the regulation of the RING domain of $\mathrm{Mdm} 2$, and the role of $\mathrm{MdmX}$ in this process is still unclear. Therefore, it is essential to fully understand how the RING domain of $\mathrm{Mdm} 2$ regulates $\mathrm{p} 53$; whether it is an independent mechanism whereby Mdm2 modifies p53 directly by ubiquitination and degradation, or whether $\mathrm{Mdm} 2$ requires $\mathrm{MdmX}$ binding in order to regulate $\mathrm{p} 53$ activity by the Mdm2-MdmX heterodimer. Recent studies using MdmX RING mutant knockin mouse models can account for part of the story. They show that Mdm2 with an intact RING domain and intrinsic E3 ligase activity are not sufficient for the inhibition of p53 activity in the absence of interaction with MdmX. These studies provide the first in vivo evidence that the association of Mdm2 with MdmX, but not the Mdm2 E3 ligase activity, is necessary for p53 control, at least in the developmental stage of mice, which is consistent with previous data based on in vitro experiments. Nevertheless, several questions still remain: Whether degradation must occur in order for p53 to be rendered inactive, or whether ubiquitination without degradation is sufficient for the inhibition of $\mathrm{p} 53$, how the Mdm2-MdmX heterodimer enables Mdm2 to be more efficiently ubiquitinating p53, and whether the Mdm2-MdmX heterodimer affects p53 ubiquitination. Although much has already been learned about the regulation of p53 by $\mathrm{Mdm} 2$ and $\mathrm{MdmX}$, much still remains unknown. Crystal structure studies are needed to further understand at the molecular level how exactly the Mdm2-MdmX-p53 ternary complex is formed and why the Mdm2-MdmX complex is a more efficient E3 ligase complex than Mdm2 alone. The histone acetyltransferase PCAF [75] has been identified as an E3 ubiquitin ligase that mediates the degradation of $\mathrm{Mdm} 2$. However, can Mdm2 be ubiquitinated and degraded by an as yet undefined E3 ubiquitin ligase? Under which circumstances is p53 monoubiquitinated and polyubiquitinated? Do Mdm2 and MdmX have additional functions independent of regulating p53? The answers to these questions will be important for understanding the importance of the Mdm2$\mathrm{MdmX}$ heterodimer in tumorigenesis and for determining the feasibility of the Mdm2-MdmX heterodimer as a target for cancer therapy.

\section{REFERENCES}

1. Miliani de Marval, PL \& Zhang, Y. The RP-Mdm2-p53 pathway and tumorigenesis. Oncotarget. 2011; 2: 234-238.

2. Vousden, KH \& Prives, C. Blinded by the Light: The Growing Complexity of p53. Cell. 2009; 137: 413-431.

3. Kruse, JP \& Gu, W. Modes of p53 regulation. Cell. 2009; 137: 609-622.

4. Menendez, S, Goh, AM, Camus, S, Ng, KW, Kua, N, Badal, V \& Lane, DP. MDM4 downregulates p53 transcriptional activity and response to stress during differentiation. Cell Cycle. 2011; 10: 1100-1108.

5. Fakharzadeh, SS, Trusko, SP \& George, DL. Tumorigenic 
potential associated with enhanced expression of a gene that is amplified in a mouse tumor cell line. EMBO J. 1991; 10: 1565-1569.

6. Momand, J, Zambetti, GP, Olson, DC, George, D \& Levine, AJ. The mdm-2 oncogene product forms a complex with the p53 protein and inhibits p53-mediated transactivation. Cell. 1992; 69: 1237-1245.

7. Joazeiro, CA \& Weissman, AM. RING finger proteins: mediators of ubiquitin ligase activity. Cell. 2000; 102: 549552.

8. Haupt, Y, Maya, R, Kazaz, A \& Oren, M. Mdm2 promotes the rapid degradation of p53. Nature. 1997; 387: 296-299.

9. Honda, R \& Yasuda, H. Activity of MDM2, a ubiquitin ligase, toward p53 or itself is dependent on the RING finger domain of the ligase. Oncogene. 2000; 19: 1473-1476.

10. Kubbutat, MH, Jones, SN \& Vousden, KH. Regulation of p53 stability by Mdm2. Nature. 1997; 387: 299-303.

11. Oliner, JD, Pietenpol, JA, Thiagalingam, S, Gyuris, J, Kinzler, KW \& Vogelstein, B. Oncoprotein MDM2 conceals the activation domain of tumour suppressor p53. Nature. 1993; 362: 857-860.

12. Itahana, K, Mao, H, Jin, A, Itahana, Y, Clegg, HV, Lindstrom, MS, Bhat, KP, Godfrey, VL, Evan, GI \& Zhang, Y. Targeted inactivation of Mdm2 RING finger E3 ubiquitin ligase activity in the mouse reveals mechanistic insights into p53 regulation. Cancer Cell. 2007; 12: 355366.

13. Shvarts, A, Steegenga, WT, Riteco, N, van Laar, T, Dekker, P, Bazuine, M, van Ham, RC, van der Houven van Oordt, W, Hateboer, G, van der Eb, AJ \& Jochemsen, AG. MDMX: a novel p53-binding protein with some functional properties of MDM2. EMBO J. 1996; 15: 5349-5357.

14. Zdzalik, M, Pustelny, K, Kedracka-Krok, S, Huben, K, Pecak, A, Wladyka, B, Jankowski, S, Dubin, A, Potempa, J \& Dubin, G. Interaction of regulators Mdm2 and Mdmx with transcription factors p53, p63 and p73. Cell Cycle. 2010; 9: 4584-4591.

15. Danovi, D, Meulmeester, E, Pasini, D, Migliorini, D, Capra, M, Frenk, R, de Graaf, P, Francoz, S, Gasparini, P, Gobbi, A, Helin, K, Pelicci, PG, Jochemsen, AG \& Marine, JC. Amplification of Mdmx (or Mdm4) directly contributes to tumor formation by inhibiting p53 tumor suppressor activity. Mol Cell Biol. 2004; 24: 5835-5843.

16. Honda, R, Tanaka, H \& Yasuda, H. Oncoprotein MDM2 is a ubiquitin ligase E3 for tumor suppressor p53. FEBS Lett. 1997; 420: 25-27.

17. Fang, S, Jensen, JP, Ludwig, RL, Vousden, KH \& Weissman, AM. Mdm2 is a RING finger-dependent ubiquitin protein ligase for itself and p53. J Biol Chem. 2000; 275: 8945-8951.

18. Pan, $\mathrm{Y} \&$ Chen, J. MDM2 promotes ubiquitination and degradation of MDMX. Mol Cell Biol. 2003; 23: 51135121.

19. Tanimura, S, Ohtsuka, S, Mitsui, K, Shirouzu, K,
Yoshimura, A \& Ohtsubo, M. MDM2 interacts with MDMX through their RING finger domains. FEBS Lett. 1999; 447: 5-9.

20. Sharp, DA, Kratowicz, SA, Sank, MJ \& George, DL. Stabilization of the MDM2 oncoprotein by interaction with the structurally related MDMX protein. J Biol Chem. 1999; 274: 38189-38196.

21. Jackson, MW \& Berberich, SJ. MdmX protects $\mathrm{p} 53$ from Mdm2-mediated degradation. Mol Cell Biol. 2000; 20: 1001-1007.

22. Stad, R, Ramos, YF, Little, N, Grivell, S, Attema, J, van Der Eb, AJ \& Jochemsen, AG. Hdmx stabilizes Mdm2 and p53. J Biol Chem. 2000; 275: 28039-28044.

23. Uldrijan, S, Pannekoek, WJ \& Vousden, KH. An essential function of the extreme C-terminus of MDM2 can be provided by MDMX. EMBO J. 2007; 26: 102-112.

24. Poyurovsky, MV, Priest, C, Kentsis, A, Borden, KL, Pan, ZQ, Pavletich, N \& Prives, C. The Mdm2 RING domain $\mathrm{C}$-terminus is required for supramolecular assembly and ubiquitin ligase activity. EMBO J. 2007; 26: 90-101.

25. Kawai, H, Lopez-Pajares, V, Kim, MM, Wiederschain, D \& Yuan, ZM. RING domain-mediated interaction is a requirement for MDM2's E3 ligase activity. Cancer Res. 2007; 67: 6026-6030.

26. Linares, LK, Hengstermann, A, Ciechanover, A, Muller, S \& Scheffner, M. HdmX stimulates Hdm2-mediated ubiquitination and degradation of p53. Proc Natl Acad Sci U S A. 2003; 100: 12009-12014.

27. Gu, J, Kawai, H, Nie, L, Kitao, H, Wiederschain, D, Jochemsen, AG, Parant, J, Lozano, G \& Yuan, ZM. Mutual dependence of MDM2 and MDMX in their functional inactivation of p53. J Biol Chem. 2002; 277: 19251-19254.

28. Marine, JC, Francoz, S, Maetens, M, Wahl, G, Toledo, F \& Lozano, G. Keeping p53 in check: essential and synergistic functions of Mdm2 and Mdm4. Cell Death Differ. 2006; 13: 927-934.

29. Xiong, S, Van Pelt, CS, Elizondo-Fraire, AC, Liu, G \& Lozano, G. Synergistic roles of Mdm2 and Mdm4 for p53 inhibition in central nervous system development. Proc Natl Acad Sci U S A. 2006; 103: 3226-3231.

30. Wade, M, Wang, YV \& Wahl, GM. The p53 orchestra: Mdm2 and Mdmx set the tone. Trends Cell Biol. 2010; 20: 299-309.

31. Wang, X. p53 regulation: Teamwork between RING domains of Mdm2 and MdmX. Cell Cycle. 2011; 10: 42254229.

32. Huang, L, Yan, Z, Liao, X, Li, Y, Yang, J, Wang, ZG, Zuo, Y, Kawai, H, Shadfan, M, Ganapathy, S \& Yuan, ZM. The p53 inhibitors MDM2/MDMX complex is required for control of p53 activity in vivo. Proc Natl Acad Sci U S A. 2011; 108: 12001-12006.

33. Pant, V, Xiong, S, Iwakuma, T, Quintas-Cardama, A \& Lozano, G. Heterodimerization of Mdm2 and Mdm4 is critical for regulating p53 activity during embryogenesis but 
dispensable for p53 and Mdm2 stability. Proc Natl Acad Sci U S A. 2011; 108: 11995-12000.

34. Stad, R, Little, NA, Xirodimas, DP, Frenk, R, van der Eb, AJ, Lane, DP, Saville, MK \& Jochemsen, AG. Mdmx stabilizes p53 and Mdm2 via two distinct mechanisms. EMBO Rep. 2001; 2: 1029-1034.

35. Migliorini, D, Danovi, D, Colombo, E, Carbone, R, Pelicci, PG \& Marine, JC. Hdmx recruitment into the nucleus by $\mathrm{Hdm} 2$ is essential for its ability to regulate p53 stability and transactivation. J Biol Chem. 2002; 277: 7318-7323.

36. Wang, YV, Wade, M, Wong, E, Li, YC, Rodewald, LW \& Wahl, GM. Quantitative analyses reveal the importance of regulated Hdmx degradation for p53 activation. Proc Natl Acad Sci U S A. 2007; 104: 12365-12370.

37. Linke, K, Mace, PD, Smith, CA, Vaux, DL, Silke, J \& Day, CL. Structure of the MDM2/MDMX RING domain heterodimer reveals dimerization is required for their ubiquitylation in trans. Cell Death Differ. 2008; 15: 841848.

38. Barak, Y, Juven, T, Haffner, R \& Oren, M. mdm2 expression is induced by wild type p53 activity. EMBO J. 1993; 12: 461-468.

39. Perry, ME, Piette, J, Zawadzki, JA, Harvey, D \& Levine, AJ. The mdm-2 gene is induced in response to UV light in a p53-dependent manner. Proc Natl Acad Sci U S A. 1993; 90: 11623-11627.

40. Carter, S, Bischof, O, Dejean, A \& Vousden, KH. C-terminal modifications regulate MDM2 dissociation and nuclear export of p53. Nat Cell Biol. 2007; 9: 428-435.

41. Li, M, Brooks, CL, Wu-Baer, F, Chen, D, Baer, R \& Gu, W. Mono- versus polyubiquitination: differential control of p53 fate by Mdm2. Science. 2003; 302: 1972-1975.

42. Stommel, JM \& Wahl, GM. Accelerated MDM2 autodegradation induced by DNA-damage kinases is required for p53 activation. EMBO J. 2004; 23: 1547-1556.

43. de Graaf, P, Little, NA, Ramos, YF, Meulmeester, E, Letteboer, SJ \& Jochemsen, AG. Hdmx protein stability is regulated by the ubiquitin ligase activity of Mdm2. J Biol Chem. 2003; 278: 38315-38324.

44. Kawai, H, Wiederschain, D, Kitao, H, Stuart, J, Tsai, KK \& Yuan, ZM. DNA damage-induced MDMX degradation is mediated by MDM2. J Biol Chem. 2003; 278: 4594645953.

45. Sabbatini, P \& McCormick, F. MDMX inhibits the p300/ CBP-mediated acetylation of p53. DNA Cell Biol. 2002; 21: 519-525.

46. Lee, JT \& Gu, W. The multiple levels of regulation by p53 ubiquitination. Cell Death Differ. 2010; 17: 86-92.

47. Kostic, M, Matt, T, Martinez-Yamout, MA, Dyson, HJ \& Wright, PE. Solution structure of the Hdm2 C2H2C4 RING, a domain critical for ubiquitination of p53. J Mol Biol. 2006; 363: 433-450.

48. Ye, Y \& Rape, M. Building ubiquitin chains: E2 enzymes at work. Nat Rev Mol Cell Biol. 2009; 10: 755-764.
49. Saville, MK, Sparks, A, Xirodimas, DP, Wardrop, J, Stevenson, LF, Bourdon, JC, Woods, YL \& Lane, DP. Regulation of p53 by the ubiquitin-conjugating enzymes UbcH5B/C in vivo. J Biol Chem. 2004; 279: 42169-42181.

50. David, Y, Ternette, N, Edelmann, MJ, Ziv, T, Gayer, B, Sertchook, R, Dadon, Y, Kessler, BM \& Navon, A. E3 Ligases Determine the Ubiquitination Site and Conjugate Type by Enforcing Specificity on E2 Enzymes. J Biol Chem. 2011;

51. Cheng, Q \& Chen, J. Mechanism of p53 stabilization by ATM after DNA damage. Cell Cycle. 2010; 9: 472-478.

52. Inuzuka, H, Fukushima, H, Shaik, S \& Wei, W. Novel insights into the molecular mechanisms governing Mdm2 ubiquitination and destruction. Oncotarget. 2010; 1: 685690.

53. Meek, DW. Tumour suppression by p53: a role for the DNA damage response? Nat Rev Cancer. 2009; 9: 714-723.

54. Waning, DL, Lehman, JA, Batuello, CN \& Mayo, LD. Controlling the Mdm2-Mdmx-p53 Circuit. Pharmaceuticals (Basel). 2010; 3: 1576-1593.

55. Cheng, Q, Chen, L, Li, Z, Lane, WS \& Chen, J. ATM activates $\mathrm{p} 53$ by regulating MDM2 oligomerization and E3 processivity. EMBO J. 2009; 28: 3857-3867.

56. Chen, L, Gilkes, DM, Pan, Y, Lane, WS \& Chen, J. ATM and Chk2-dependent phosphorylation of MDMX contribute to 553 activation after DNA damage. EMBO J. 2005; 24 : 3411-3422.

57. Okamoto, K, Kashima, K, Pereg, Y, Ishida, M, Yamazaki, S, Nota, A, Teunisse, A, Migliorini, D, Kitabayashi, I, Marine, JC, Prives, C, Shiloh, Y, Jochemsen, AG \& Taya, Y. DNA damage-induced phosphorylation of $\mathrm{MdmX}$ at serine 367 activates $\mathrm{p} 53$ by targeting $\mathrm{MdmX}$ for Mdm2dependent degradation. Mol Cell Biol. 2005; 25: 96089620.

58. LeBron, C, Chen, L, Gilkes, DM \& Chen, J. Regulation of MDMX nuclear import and degradation by Chk2 and 14-33. EMBO J. 2006; 25: 1196-1206.

59. Pereg, Y, Lam, S, Teunisse, A, Biton, S, Meulmeester, E, Mittelman, L, Buscemi, G, Okamoto, K, Taya, Y, Shiloh, Y \& Jochemsen, AG. Differential roles of ATM- and Chk2mediated phosphorylations of Hdmx in response to DNA damage. Mol Cell Biol. 2006; 26: 6819-6831.

60. Zhang, X, Lin, L, Guo, H, Yang, J, Jones, SN, Jochemsen, A \& Lu, X. Phosphorylation and degradation of MdmX is inhibited by Wip1 phosphatase in the DNA damage response. Cancer Res. 2009; 69: 7960-7968.

61. Lu, X, Nguyen, TA, Zhang, X \& Donehower, LA. The Wip1 phosphatase and Mdm2: cracking the "Wip" on p53 stability. Cell Cycle. 2008; 7: 164-168.

62. Wang, YV, Leblanc, M, Wade, M, Jochemsen, AG \& Wahl, GM. Increased radioresistance and accelerated B cell lymphomas in mice with Mdmx mutations that prevent modifications by DNA-damage-activated kinases. Cancer Cell. 2009; 16: 33-43. 
63. Li, B, Cheng, Q, Li, Z \& Chen, J. p53 inactivation by Biol. 2007; 9: 331-338. MDM2 and MDMX negative feedback loops in testicular germ cell tumors. Cell Cycle. 2010; 9: 1411-1420.

64. Azmi, AS, Banerjee, S, Ali, S, Wang, Z, Bao, B, Beck, FW, Maitah, M, Choi, M, Shields, TF, Philip, PA, Sarkar, FH \& Mohammad, RM. Network modeling of MDM2 inhibitoroxaliplatin combination reveals biological synergy in wtp53 solid tumors. Oncotarget. 2011; 2: 378-392.

65. Vassilev, LT, Vu, BT, Graves, B, Carvajal, D, Podlaski, F, Filipovic, Z, Kong, N, Kammlott, U, Lukacs, C, Klein, C, Fotouhi, N \& Liu, EA. In vivo activation of the p53 pathway by small-molecule antagonists of MDM2. Science. 2004; 303: 844-848.

66. Apontes, P, Leontieva, OV, Demidenko, ZN, Li, F \& Blagosklonny, MV. Exploring long-term protection of normal human fibroblasts and epithelial cells from chemotherapy in cell culture. Oncotarget. 2011; 2: 222-233.

67. Rao, B, van Leeuwen, IM, Higgins, M, Campbel, J, Thompson, AM, Lane, DP \& Lain, S. Evaluation of an Actinomycin D/VX-680 aurora kinase inhibitor combination in p53-based cyclotherapy. Oncotarget. 2010; 1: 639-650.

68. Marine, JC \& Lozano, G. Mdm2-mediated ubiquitylation: p53 and beyond. Cell Death Differ. 2010; 17: 93-102.

69. Bernal, F, Wade, M, Godes, M, Davis, TN, Whitehead, DG, Kung, AL, Wahl, GM \& Walensky, LD. A stapled p53 helix overcomes HDMX-mediated suppression of p53. Cancer Cell. 2010; 18: 411-422.

70. Joseph, TL, Madhumalar, A, Brown, CJ, Lane, DP \& Verma, CS. Differential binding of p53 and nutlin to MDM2 and MDMX: computational studies. Cell Cycle. 2010; 9: 1167-1181.

71. Popowicz, GM, Czarna, A, Wolf, S, Wang, K, Wang, W, Domling, A \& Holak, TA. Structures of low molecular weight inhibitors bound to MDMX and MDM2 reveal new approaches for p53-MDMX/MDM2 antagonist drug discovery. Cell Cycle. 2010; 9: 1104-1111.

72. Joseph, TL, Lane, D \& Verma, CS. Stapled peptides in the p53 pathway: computer simulations reveal novel interactions of the staples with the target protein. Cell Cycle. 2010; 9: 4560-4568.

73. Yang, Y, Li, CC \& Weissman, AM. Regulating the p53 system through ubiquitination. Oncogene. 2004; 23: 20962106.

74. Yang, Y, Ludwig, RL, Jensen, JP, Pierre, SA, Medaglia, MV, Davydov, IV, Safiran, YJ, Oberoi, P, Kenten, JH, Phillips, AC, Weissman, AM \& Vousden, KH. Small molecule inhibitors of HDM2 ubiquitin ligase activity stabilize and activate p53 in cells. Cancer Cell. 2005; 7: 547-559.

75. Linares, LK, Kiernan, R, Triboulet, R, Chable-Bessia, C, Latreille, D, Cuvier, O, Lacroix, M, Le Cam, L, Coux, O \& Benkirane, M. Intrinsic ubiquitination activity of PCAF controls the stability of the oncoprotein Hdm2. Nat Cell 